\title{
HISTORY AND CURRENT STATUS OF THE MICROWAVE ELECTROTHERMAL THRUSTER
}

\author{
M. M. Micci, S. G. Bilén, and D. E. Clemens
}

The microwave electrothermal thruster (MET) heats a propellant by means of a free-floating microwave-generated plasma within a microwave resonant cavity followed by a gasdynamic nozzle expansion. The MET design is detailed along with computational electromagnetic modeling of various resonant cavities. Performance of thrusters operating at microwave frequencies of $2.45,7.5$, and $14 \mathrm{GHz}$ at power levels between 10 and $2500 \mathrm{~W}$ is discussed. Measurements of thruster electromagnetic interference (EMI) indicate that the thruster emits a very low level of EMI compared to other electric propulsion devices. Laboratory measurements of exhaust velocity, thrust, and specific impulse for several propellants are presented.

\section{INTRODUCTION}

The MET is an electric propulsion device that uses microwaves to heat a gaseous propellant. Microwave energy is fed into an electromagnetic resonant cavity to ignite and sustain a free-floating plasma, which heats the propellant gas. The heated propellant is then accelerated through a gasdynamic nozzle and exhausted to generate thrust. The heating mechanism is similar to that of an arcjet, which utilizes an arc discharge formed between two electrodes to heat a propellant gas. The main difference is that the MET plasma is free-floating and thus the system does not suffer from the lifetime-limiting electrode erosion problems that are characteristic of the arcjet. The MET offers thrust and specific impulse comparable to arcjets operating at the same power level with higher efficiency and longer lifetimes.

\subsection{Basic Operational Principles}

The MET shown schematically in Fig. 1 consists of a circular cross section resonant cavity operating in the $\mathrm{TM}_{011}^{\mathrm{z}}$ mode. This resonant mode shown in Fig. 2

This is an Open Access article distributed under the terms of the Creative Commons Attribution-Noncommercial License 3.0, which permits unrestricted use, distribution, and reproduction in any noncommercial medium, provided the original work is properly cited. 


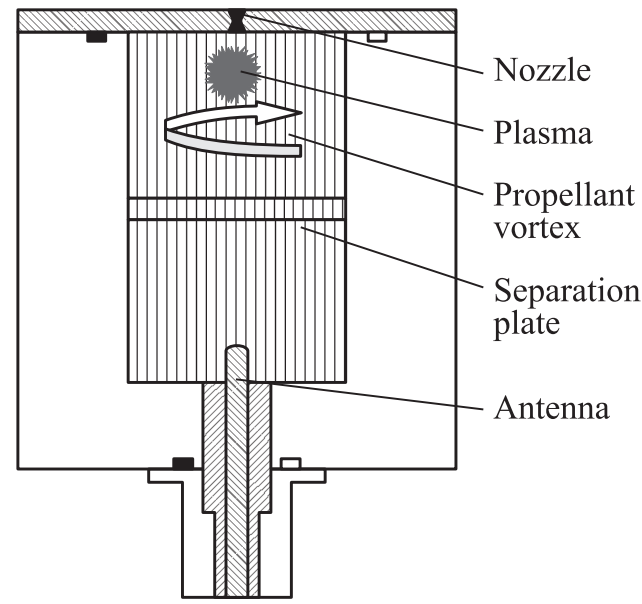

Figure 1 Schematic diagram of the MET

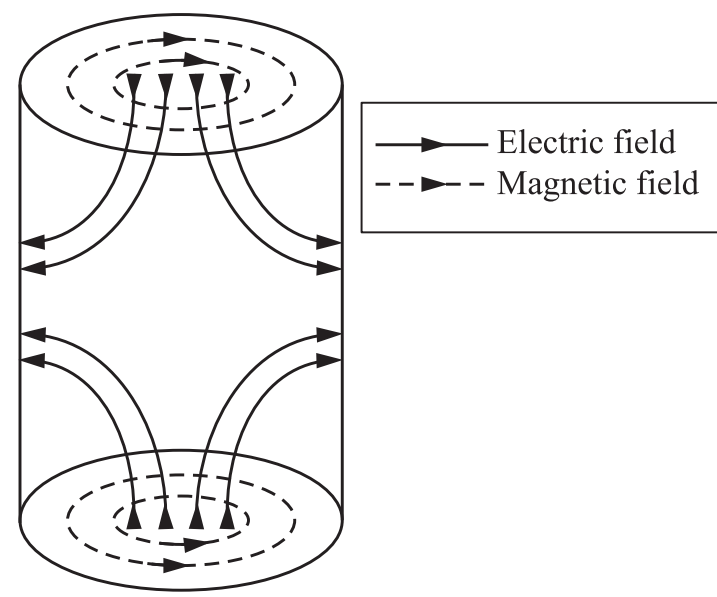

Figure 2 Electromagnetic field configuration for the $\mathrm{TM}_{011}^{\mathrm{z}}$ mode in the empty MET cavity

for an empty cavity is characterized by regions of high electric energy density on the cavity axis at the endplates, and in the annular region circumscribing the cavity midplane. Properly selecting the height-to-diameter ratio of the cavity causes the electric energy density at the endplates to be much greater than at the midplane. 
The resonant cavity is essentially a circular cross section waveguide shorted by two conducting endplates. One endplate contains a nozzle and the other contains an antenna for inputting microwave power, each along the cavity axis. The cavity is partitioned by a dielectric separation plate that allows the two halves of the cavity to be maintained at different pressures. Microwave energy is fed into the cavity via the antenna. Some portion of the forward power is reflected and the remainder is assumed to be absorbed by the plasma. Ohmic heating of the walls is assumed to be negligible compared to the forward power because the walls are good conductors.

Propellant is injected into the nozzle section and a free-floating plasma forms in the region of high electric energy density at the nozzle entrance. For low levels of microwave power, plasma ignition only occurs at low pressures $(<6 \mathrm{kPa})$. However, once ignited, the plasma can be sustained at high pressures. The propellant is injected tangentially to form a vortex flow inside the chamber, which cools the chamber walls and aids the plasma stabilization due to the generated radial pressure gradient that helps to maintain the plasma centered on the cavity axis. The propellant flowing around the plasma is heated and exhausted through a choked nozzle.

Since plasma ignition only occurs at low pressures, the antenna section is maintained at atmospheric pressure. This prevents plasma formation near the antenna that is in the other region of high electric energy density. This also reduces mechanical stress on the separation plate by decreasing the pressure differential across it when the chamber pressure is high.

\section{THRUSTER DESIGNS AND PERFORMANCE RESULTS}

\section{$2.1 \quad 2.45-G i g a h e r t z$ Thrusters}

Research on the MET began at The Michigan State University and The Pennsylvania State University in the 1980s [1, 2]. These thrusters were designed to operate with an input power between 1 and $2.5 \mathrm{~kW}$ provided by a magnetron at a microwave frequency of $2.45 \mathrm{GHz}$. This frequency resulted in resonant cavity dimensions of $15.75 \mathrm{~cm}$ in length and $10 \mathrm{~cm}$ in internal diameter. Early work demonstrated the feasibility of the concept using variable-geometry resonant cavities in which cavity impedance was actively tuned. Observations of chamber characteristics showed that it could be used effectively as a propulsion device. Plasmas were ignited and sustained with hydrogen, helium, nitrogen, oxygen, ammonia, water vapor, methane, and simulated cold hydrazine decomposition products. Spectroscopic diagnostics of the cavity plasma indicated electron temperatures of 10,000-12,000 K, insensitive to operating conditions [3, 4]. A fixed- 


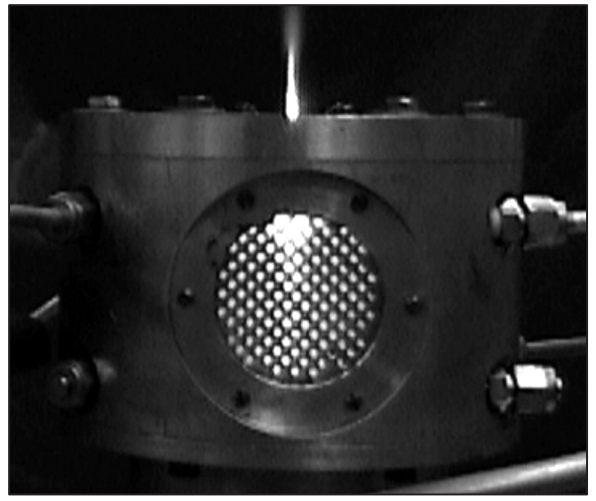

(a)

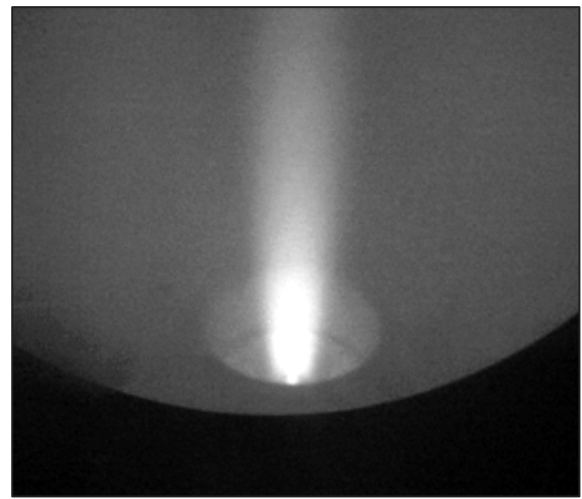

(b)

Figure 3 Kilowatt-class 2.45-gigahertz thruster operating with nitrogen propellant exhausting into atmospheric pressure $(a)$ and into vacuum $(b)$

geometry cavity was then built and operated $[5,6]$. Excellent performance was demonstrated using this simpler, more practical design. The estimated powerto-dry mass ratio of a 2-kilowatt propulsion system is $513 \mathrm{~W} / \mathrm{kg}$, compared to only $235 \mathrm{~W} / \mathrm{kg}$ for an Aerojet MR-512 arcjet propulsion system. To date, this design has remained largely unchanged.

Recent work on the high-power (kW-class) 2.45-gigahertz MET includes an emission thermometry study using oxygen and nitrogen propellants [7]. Figure $3 a$ shows the thruster operating with nitrogen propellant exhausting to atmospheric pressure and Fig. $3 b$ shows a vacuum expansion. Spatially resolved emission spectra were obtained experimentally and compared to temperaturedependent emission models. From this comparison, rotational temperatures, and thus translational temperatures, of the MET plasmas were determined. Rotational temperatures of $2000 \mathrm{~K}$ for $\mathrm{O}_{2}$ and $5500 \mathrm{~K}$ for $\mathrm{N}_{2}^{+}$were measured and found to be nearly constant over a range of operating conditions.

\section{$2.2 \quad$ 7.5-Gigahertz Thrusters}

Research at Penn State on the low-power $(\sim 100 \mathrm{~W})$ 7.5-gigahertz MET was initiated in 1997 and focused on characterizing chamber conditions and obtaining thrust and specific impulse measurements using helium, nitrogen, and ammonia propellants [8-10]. The thruster was a scaled-down version of the one developed during previous high-power prototype testing and the design was intended for use on small spacecraft requiring low-power, low-thrust propulsion capabilities. At the higher microwave frequency of $7.5 \mathrm{GHz}$, the resonant cavity dimensions 


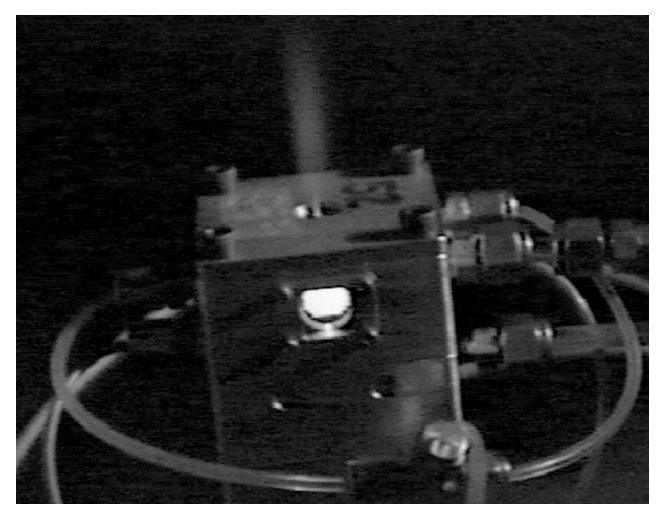

Figure 4 7.5-gigahertz thruster operating at $80 \mathrm{~W}$ with helium

are $5.15 \mathrm{~cm}$ long and $3.2 \mathrm{~cm}$ in inner diameter (ID). Both magnetrons and traveling wave tube amplifiers (TWTA) have been used as the microwave power source. It performed well in vacuum, demonstrating that it could be run autonomously under realistic space conditions for extended periods.

Figure 4 shows the thruster operating in vacuum with helium propellant and $75 \mathrm{~W}$ of power at $7.5 \mathrm{GHz}$. Testing with helium, nitrogen, and ammonia resulted in chamber pressures as high as 372,379 , and $49 \mathrm{kPa}$, respectively, and coupling efficiencies as high as $99 \%$. Using the mass flow equation and measurements of chamber pressure under cold flow and hot fire conditions, maximum mean chamber temperatures of $1700 \mathrm{~K}$ for helium, $2100 \mathrm{~K}$ for nitrogen, and $1240 \mathrm{~K}$ for ammonia were calculated. Doppler shift measurements of centerline exhaust velocity and, hence, specific impulse were performed in vacuum using helium with an input power of $80 \mathrm{~W}$. Centerline specific impulses, ranging from 730 to $1330 \mathrm{~s}$, increased with increasing specific power, which ranged from 15 to $30 \mathrm{MJ} / \mathrm{kg}$ (Fig. 5). Spectroscopic measurements of electron temperature in helium propellant were also performed using the relative line intensity method. The assumption of local thermodynamic equilibrium (LTE) is commonly made for systems at or above pressures of $1 \mathrm{~atm}$; however, a high degree of nonequilibrium was observed even at pressures of 2 atm. At $345 \mathrm{kPa}$, the LTE assumption was validated with measured electron temperatures of $4005 \mathrm{~K} \pm 18 \%$.

The latest development of the 7.5-gigahertz MET involved the use of simulated (cold) hydrazine decomposition products as the propellant [11]. Hydrazine is an attractive propellant due to its storability as a liquid, low molecular weight, and initial heat release when decomposed by a catalyst bed. The composition of the decomposed hydrazine is given by

$$
3 \mathrm{~N}_{2} \mathrm{H}_{4} \rightarrow 4(1-X) \mathrm{NH}_{3}+(2 X+1) \mathrm{N}_{2}+6 X \mathrm{H}_{2}
$$




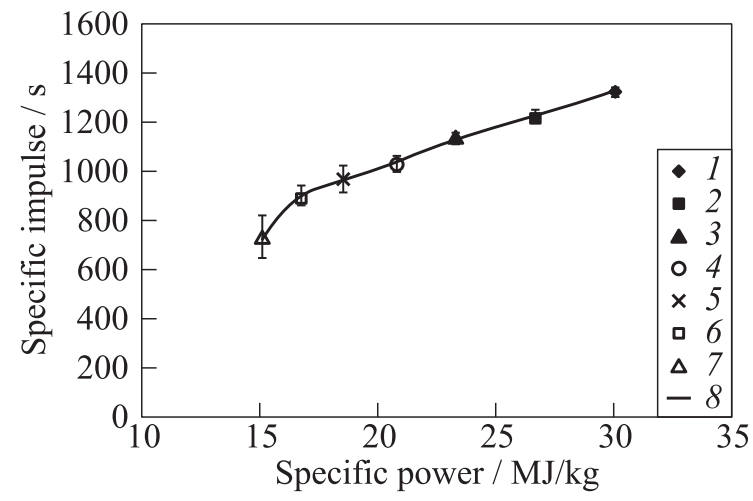

Figure 5 Nozzle centerline specific impulse vs. specific power for 7.5-gigahertz thruster operating at $80 \mathrm{~W}$ with helium: $1-3.33 \mathrm{mg} / \mathrm{s}(P=14.18 \mathrm{psia}) ; 2-$ $3.76 \mathrm{mg} / \mathrm{s}(P=16.85 \mathrm{psia}) ; 3-4.30 \mathrm{mg} / \mathrm{s}(P=18.16 \mathrm{psia}) ; 4-4.84 \mathrm{mg} / \mathrm{s}$ $(P=21.72 \mathrm{psia}) ; 5-5.38 \mathrm{mg} / \mathrm{s}(P=23.74 \mathrm{psia}) ; 6-6.02 \mathrm{mg} / \mathrm{s}(P=27.00 \mathrm{psia}) ;$ $7-6.65 \mathrm{mg} / \mathrm{s}(P=36.90 \mathrm{psia})$; and $8-$ trendline

where $X$ is the degree of ammonia dissociation with $X=0$ corresponding to $0 \%$ and $X=1$ corresponding to $100 \%$. The degree to which the ammonia dissociates is a function of system characteristics and affects the composition temperature and therefore the specific impulse. Thrust and specific impulse under vacuum conditions was measured using a momentum trap for $X$ values of 0.0 , 0.4 , and 1.0 .

Figure $6 a$ plots measured thrust as a function of chamber pressure for $105 \mathrm{~W}$ of input microwave power for the three values of $X$ along with the theoretical ideal thrust calculated with the measured chamber pressure and temperature, nozzle geometry, and discharge coefficient. Good agreement between measured and calculated thrust values were found for $100 \%$ ammonia decomposition $(X$ $=1$ ) with lesser agreement when ammonia is contained in the propellant. This is due to the ease with which ammonia dissociates and generates frozen flow losses.

Figure $6 b$ plots measured and theoretical specific impulse as a function of specific power. Once again, the best agreement between measured and ideal values is obtained for a mixture representing complete ammonia dissociation. The specific impulse decreases with increasing specific power because thruster performance increases with increasing chamber pressure and higher specific powers were obtained by decreasing the propellant mass flow while keeping the input microwave power constant, thereby decreasing the chamber pressure. This thruster is currently being optimized to bring its thrust-to-power ratio up to a value equivalent to that of an arcjet. 


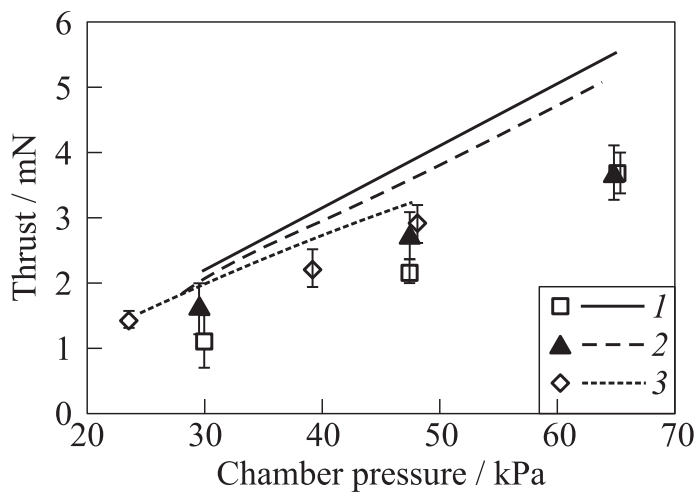

(a)

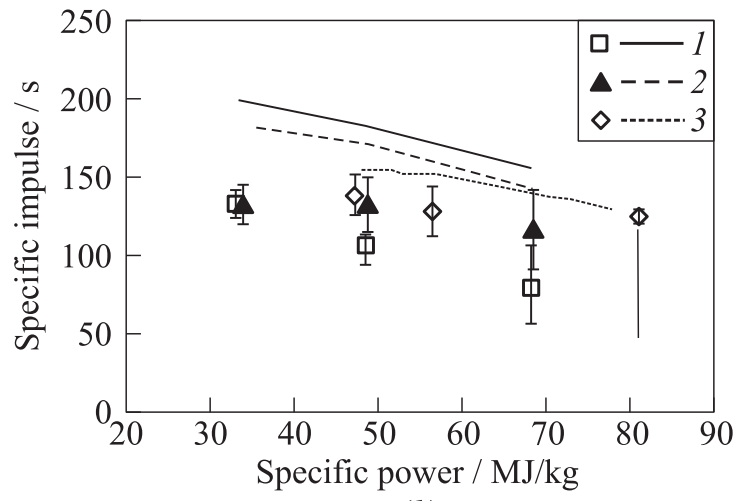

(b)

Figure 6 Thrust vs. chamber pressure $(a)$ and specific impulse vs. specific power $(b)$ for simulated hydrazine for three values of degree of ammonia dissociation: $1-x=0.0$; $2-0.4$; and $3-x=1.0$. Symbols refer to experiments and curves refer to calculations

\subsection{5-Gigahertz Thrusters}

In comparing the performance of the 2.45- and 7.5-gigahertz thrusters, it was found that the 7.5-gigahertz thruster was able to sustain a plasma at much lower levels of input microwave power. This is due to the decreased resonant cavity volume, giving a much higher power density for the same input power. Thus, going to even smaller resonant cavities by increasing the microwave frequency allows the use of even lower levels of microwave power. To validate this, a 14.5-gigahertz resonant cavity thruster was designed and constructed for use with $20 \mathrm{~W}$ of microwave power supplied by a Ku-band solid state amplifier. At this frequency, the cavity is only $2.1 \mathrm{~cm}$ long and $1.3 \mathrm{~cm}$ in ID. 


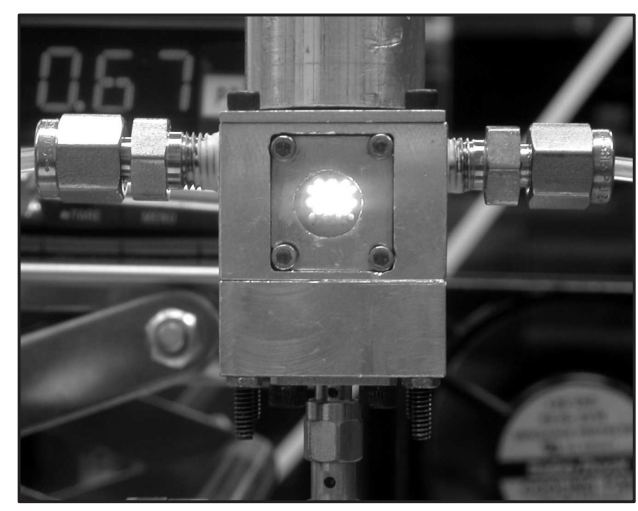

Figure 7 14.5-gigahertz thruster operating with helium propellant and $14.3 \mathrm{~W}$ of input microwave power

Figure 7 shows the 14.5-gigahertz thruster operating with helium propellant and $14.3 \mathrm{~W}$ of input microwave power at a chamber pressure of $70 \mathrm{kPa}$. Initial testing of the thruster has identified the need for a redesign of the cavity after which performance characterization will be undertaken.

\section{ELECTROMAGNETIC INTERFERENCE TESTING}

Electromagnetic interference characteristics are as important as other thruster characteristics, especially given the possible interaction between the thruster and sensitive spacecraft electronic and communication systems. Electromagnetic interference is a potential problem with the majority of current electric propulsion devices. Zakrzwski et al. measured EMI from the EO-1 pulsed plasma thruster above their specification derived from MIL-STD-461C [12]. Brinza et al. made in-space measurements of EMI from the DS1 ion thruster that also exceeded the standard [13]. Jankovsky et al. discuss the large amount of EMI emitted by Hall thrusters [14].

Electromagnetic interference characterization of the microwave thruster was completed using a 7.5-gigahertz MET. The thruster was placed inside an anechoic chamber, and extensive measurements were made on the thruster and support electronics system (power source, magnetron, couplers, etc.) using a receiving antenna and spectrum analyzer. Frequency sweeps from 1 to $19 \mathrm{GHz}$ were made to determine what fundamental and harmonic components were emitted by the thruster and support electronics under normal operating conditions. Subsequently, measurements were made with a 50-ohm microwave dummy load in place of the MET to distinguish the power emitted by the thruster 
and plasma plume from the power emitted by the support electronics components.

The anechoic chamber used in these tests is fully enclosed and its absorbent foam attenuation provides a return loss greater than $45 \mathrm{~dB}$ from 20 to $183 \mathrm{GHz}$. The chamber also provides electric field shielding of greater than $100 \mathrm{~dB}$ for frequencies above $10 \mathrm{kHz}$, and magnetic field shielding of greater than $100 \mathrm{~dB}$ for frequencies above $1 \mathrm{MHz}$. To determine the relative amount of background signal noise in the chamber and from the measurement system, ambient measurements were taken inside the anechoic chamber with the MET idle and the magnetron power disconnected. These tests indicate that the anechoic chamber properly sealed out frequencies over the $1-19 \mathrm{GHz}$ range of interest and that the spectrum analyzer itself was the limiting component in the noise floor.

Figure $8 a$ is a typical plot of the noise floor data, with the power units given in $\mathrm{dBm}$. Note that this data indicates the power measured at the spectrum analyzer and does not account for cable loss or receiving antenna gain. Horizontal polarization of the receiving antenna produced the same data as did vertical polarization. Results were:

1. A large radiated component at the magnetron's fundamental operating frequency. Due to the thruster chamber dimensions used during testing, this fundamental frequency ranged from 7.60 to $7.70 \mathrm{GHz}$ instead of the "standard" $7.50 \mathrm{GHz}$.

2. A much smaller quarter-harmonic radiated component at approximately $1.90 \mathrm{GHz}$, and one or more additional fractional-order harmonics.

3. No radiated harmonic content above the fundamental operating frequency.

Figure $8 b$ is a typical plot of the measured radiated power during MET firing tests. Note the presence of a 5.76-gigahertz harmonic, which is approximately a three-quarter harmonic of the fundamental frequency. The fundamental component power level of $-53.78 \mathrm{dBm}$ is typical of values seen during testing, although the fundamental component was measured over a range from -32 to $-55 \mathrm{dBm}$.

Figure $8 c$ gives an expanded plot of the fundamental power component as measured in the horizontal direction during an MET firing test. Note the very narrow bandwidth of this component, which was less than $50 \mathrm{MHz}$ in all tests with and without the thruster firing. In order to more accurately determine the sources of EMI measured during MET firing tests, the MET was replaced with a 50-ohm microwave dummy load and the same 1-19-gigahertz sweeps were performed.

Figure $8 d$ shows a typical data plot from a dummy load sweep with the receiving antenna oriented vertically. Statistical analysis on both data sets shows no significant difference between MET firing test and dummy load test power levels at the fundamental operating frequency in the vertical direction. Thus, the majority (if not all) of the radiated emissions can be attributed to the support 


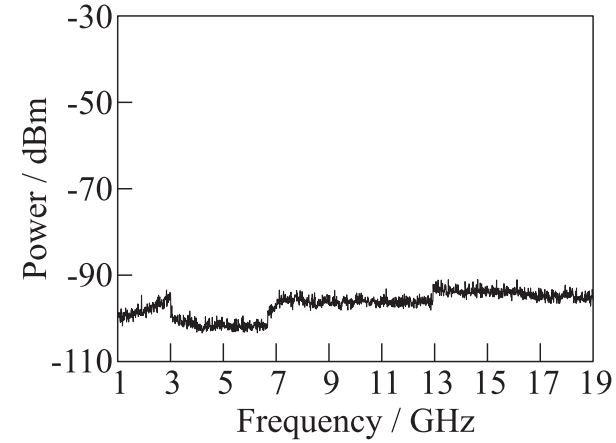

(a)

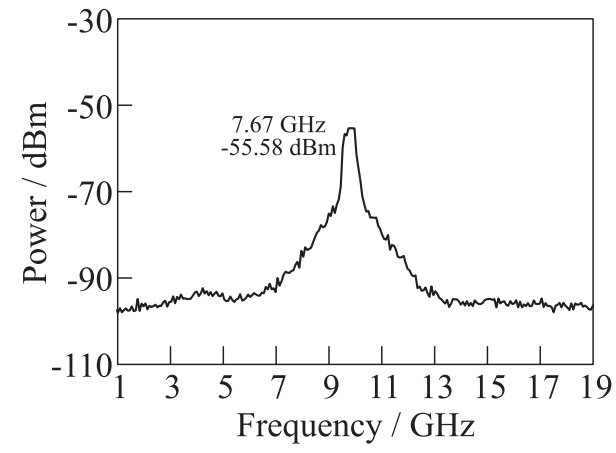

(c)

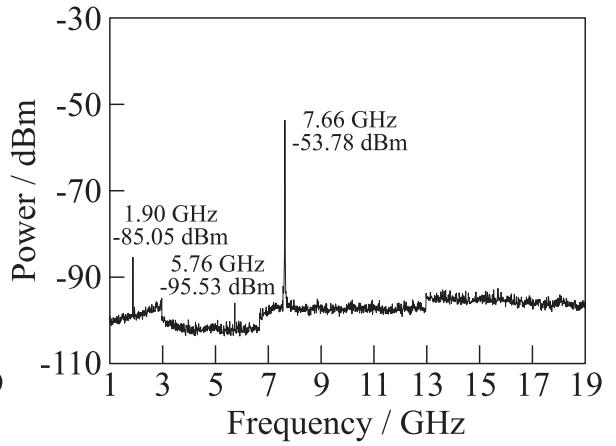

(b)

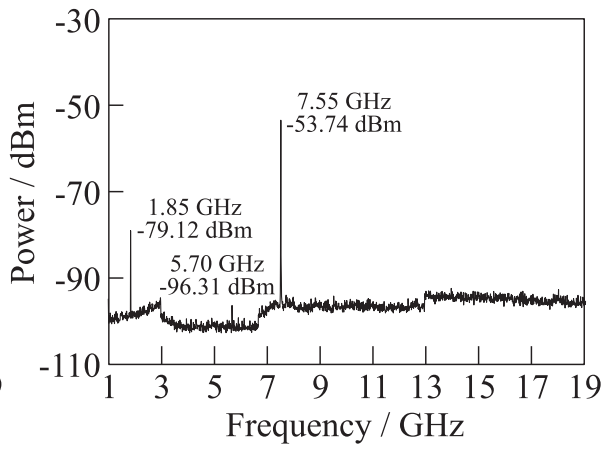

(d)

Figure 8 (a) Typical measured noise floor of measurement and anechoic chamber system (vertical antenna polarization); $(b)$ plot of typical measured radiated power levels during MET firing tests (vertical antenna polarization); (c) expanded plot of 7.67gigahertz radiated power during MET firing test (horizontal antenna polarization); and $(d)$ plot of typical measured radiated power levels during dummy load tests (vertical antenna polarization)

electronics components, and not the thruster cavity or thruster's plasma plume. Given proper shielding of the support electronics components, the MET has the ability to produce negligible radiated emissions during startup and continuous operation.

\section{RESONANT CAVITY ELECTROMAGNETIC MODELING}

Computational electromagnetics has recently been employed to aid in the design of the microwave resonant cavities [15]. The software package COMSOL Multi- 

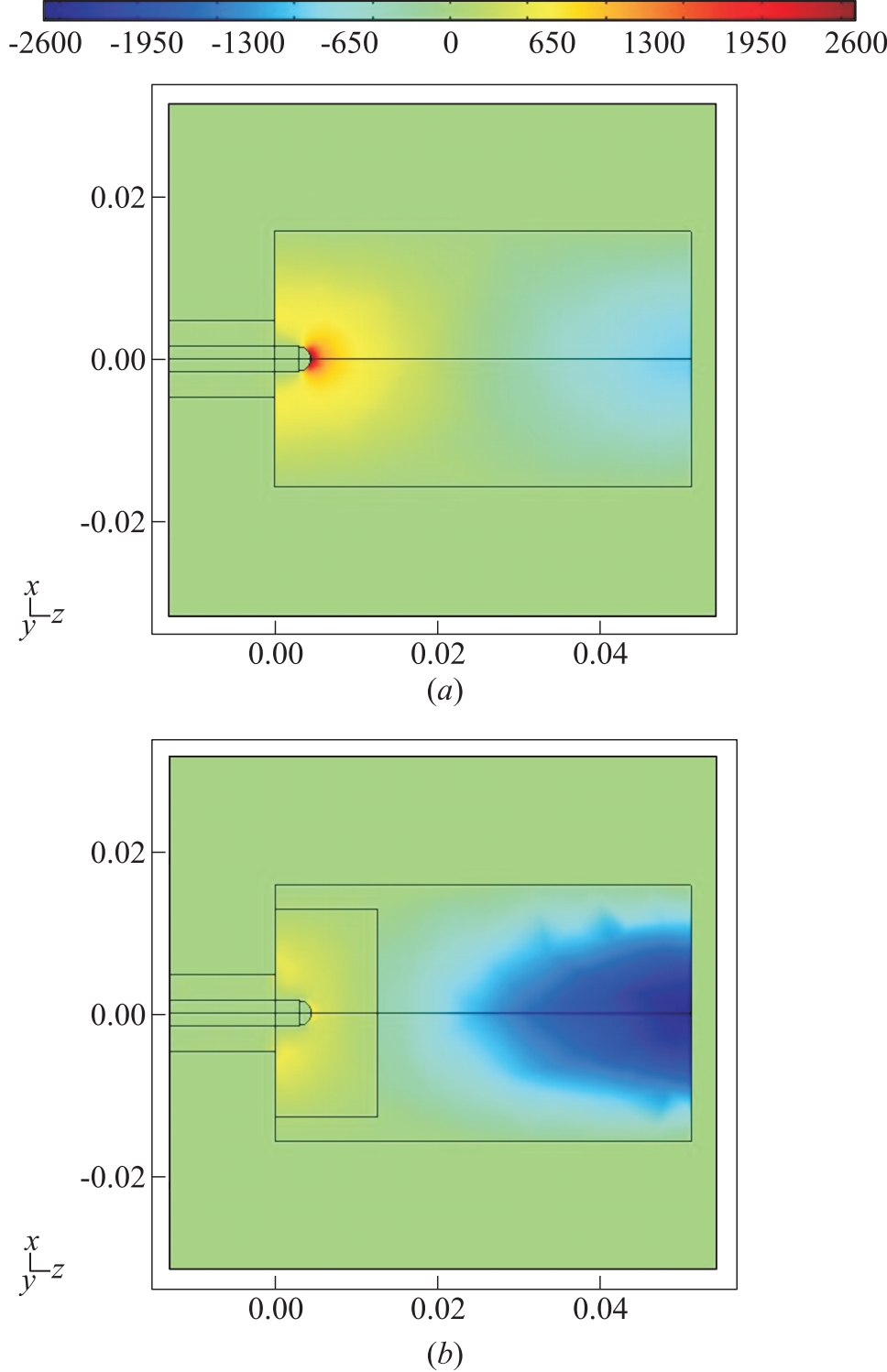

Figure 9 Axial electric field strength in an empty cavity $(a)$ and in a cavity with a dielectric antenna cover (b). (Refer Micci et al., p. 435.) 
physics was utilized to model various modifications to the thruster. COMSOL Multiphysics uses the finite-element method to solve Maxwell's equations for the electric and magnetic fields. The numerical computations were first used to make a priori calculations of the cavity resonant frequencies for comparison to experimental measurements. They were then used to examine various cavity modifications including the effects of antenna depth and tip shape, the use of a conical nozzle end to the chamber, a dielectric cover over the antenna to prevent plasma formation there, and a ceramic nozzle entrance region to enhance propellant heating.

Figure $9 a$ shows a representative result for an empty cylindrical cavity. Regions of maximum electric field can be seen at the antenna and nozzle ends of the cavity.

Figure $9 b$ shows the effect of a dielectric cover over the antenna, which acts to contain the electric field at the antenna end of the cavity within the dielectric without modifying the electric field at the nozzle end. It was found, however, that larger dielectric caps pulled the nozzle end electric field toward the midpoint of the cavity. Simulations showed that the depth of the antenna protrusion into the cavity affected both the resonant frequency and maximum electric field of the cavity and that an antenna with a hemispherical end resulted in a higher electric field than an antenna with a flat end, which is how they are procured from the manufacturer. A cavity with a conical shaped nozzle end was modeled, as such a shape could improve the heating of the propellant gas by the plasma before exiting out the nozzle but it was found that the conical end pushed the region of maximum electric field, and therefore the plasma location, away from the nozzle end toward the cavity midpoint. Simulations of a Macor ceramic nozzle entrance region showed that it further concentrated the electric field at the nozzle end. This was not, however, reproducible in experiments. It is believed that water absorbed in the Macor ceramic prevented the performance improvement.

\section{SUMMARY}

The MET has been the subject of research and development at The Pennsylvania State University since 1985 . The MET operates by heating a propellant gas by means of a free-floating microwave-generated plasma within a microwave resonant cavity followed by a converging-diverging gasdynamic nozzle expansion. Due to the electrodeless plasma, high propellant gas temperatures, and atmospheric and above chamber gas pressures, the MET is able to achieve high specific impulses, high thrust densities, and high efficiencies using a variety of propellants, including oxidizing propellants. Plasmas have been ignited and sustained with hydrogen, helium, nitrogen, oxygen, ammonia, water vapor, methane, and simulated cold hydrazine decomposition products. The history of 
the MET design leading up to its current embodiment is detailed along with computational electromagnetic modeling of various resonant cavities. Configurations and performance of thrusters designed to operate at 2.45-; 7.5-; and 14.5-gigahertz microwave frequencies at power levels between 10 and $2500 \mathrm{~W}$ are discussed. Three different means of generating the microwave energy, magnetrons, traveling wave tubes, and solid state amplifiers, have been successfully utilized. Recent measurements of thruster EMI are presented indicating that the thruster emits a very low level of EMI compared to other electric propulsion devices. Laboratory measurements of exhaust velocity via Doppler shift, as well as thrust and specific impulse for several propellants under vacuum conditions are presented.

\section{REFERENCES}

1. Micci, M. M. 1984. Prospects for microwave heated propulsion. AIAA Paper No. 1984-1390.

2. Whitehair, S., J. Asmussen, and S. Nakanishi. 1987. Microwave electrothermal thruster performance in helium gas. J. Propul. Power 3(2):136-44.

3. Balaam, Ph., and M. M. Micci. 1992. Investigation of free-floating resonant cavity microwave plasmas for propulsion. J. Propul. Power 8(1):103-9.

4. Balaam, Ph., and M. M. Micci. 1995. Investigation of stabilized resonant cavity microwave plasmas for propulsion. J. Propul. Power 11(5):1021-27.

5. Sullivan, D. J., and M. M. Micci. 1994. Performance testing and exhaust plume characterization of the microwave arcjet thruster. AIAA Paper No. 1994-3127.

6. Sullivan, D. J., J. Kline, C. Philippe, and M. M. Micci. 1995. Current status of the microwave arcjet thruster. AIAA Paper No. 1995-3065.

7. Chianese, S. G., and M. M. Micci. 2006. Microwave electrothermal thruster chamber temperature measurements and performance calculations. J. Propul. Power $22(1): 31-37$.

8. Nordling, D., and M. M. Micci. 1997. Low power microwave arcjet development. IEPC Paper No. 1997-089.

9. Nordling, D., F. Souliez, and M. M. Micci. 1998. Low-power microwave arcjet testing. AIAA Paper No. 1998-3499.

10. Souliez, F. J., S. G. Chianese, G. H. Dizac, and M. M. Micci. 2000. Low-power microwave arcjet testing: Plasma and plume diagnostics and performance evaluation. In: Micropropulsion for small spacecraft. Eds. M. M. Micci and A.D. Ketsdever. Progress in astronautics and aeronautics ser. Reston, VA: AIAA. 187:199-214.

11. Clemens, D., M. Micci, and S. Bilén. 2006. Microwave electrothermal thruster using simulated hydrazine. AIAA Paper No. 2006-5156.

12. Zakrzwski, C., M. Davis, and Ch. Sarmiento. 2001. Addressing EO-1 spacecraft pulsed plasma thruster EMI concerns. AIAA Paper No. 2001-3641. 
13. Brinza, D.E., M.D. Henry, A.T. Mactutis, K.P. McCarty, J. D. Rademacher, T. R. van Zandt, P. Narvaez, J. J. Wang, B. T. Tsurutani, I. Katz, V. A. Davis, S. Moses, G. Musmann, F. Kuhnke, I. Richter, C. Othmer, and K.-H. Glassmeier. 2001. An overview of results from the ion diagnostics sensors flown on DS1. AIAA Paper No. 2001-0966.

14. Jankovsky, R. S., D. T. Jacobson, Ch. J. Sarmiento, L. R. Piñero, D. H. Manzella, R. R. Hofer, and P. Y. Peterson. 2002. NASA's Hall thruster program 2002. AIAA Paper No. 2002-3675.

15. Bilén, S., C. Valentino, M. Micci, and D. Clemens. 2005. Numerical electromagnetic modeling of a low-power microwave electrothermal thruster. AIAA Paper No. 20053699 . 